\title{
CRISE ORGÃNICA, HEGEMONIA E REVOLUÇÃO PASSIVA GRAMSCIANA
}

\section{MARIA SOCORRO RAMOS MILITÃO' ${ }^{1}$}

RESUMO: Visando compreender os fatores que originaram o Fascismo na Itália e as derrotas do movimento operário na Europa, o filósofo italiano Antonio Gramsci promoveu uma análise microscópica desses fenômenos e das dimensões que eles atingiram no período da Primeira Guerra e no posterior, assim pôs-se a investigar os fatores que se coligaram e caracterizaram a crise, desencadeada por eles. Essas seriam algumas das questões que receberiam a atenção do autor sardo em sua obra Cadernos do Cárcere, na qual construiria preciosas anotações acerca da crise capitalista que, para ele, não seria apenas uma crise esporádica própria ao sistema, mas uma crise orgânica por ser acompanhada de perda de poder hegemônico. Naquela obra, mostra que a assim chamada crise de hegemonia também desencadeia crises econômicas, políticas, de comando, de autoridade, etc. Por isso, ela deve ser interpretada como um movimento orgânico que se desenvolve em um processo histórico complexo, com sua multiplicidade de componentes e inter-relações em nível global, e não apenas como fenômeno imediato e conjuntural, daí ser provocada por um somatório de questões que se acumularam molecularmente. $\mathrm{O}$ autor dos Cadernos aponta como fracasso da política da classe dirigente a imposição do consenso das grandes massas pela força; a organização política de grandes massas anteriormente passivas e que passam a se movimentar, embora sem uma vontade política precisa; ou ainda porque as forças antagônicas se mostraram incapazes de organizar em seu favor esta desordem. Diante desse quadro é que se apresenta o objetivo deste artigo: explicitar o processo de desenvolvimento da crise orgânica e a inerente perda de hegemonia decorrente dela, e, com efeito, demonstrar a possibilidade de construção da hegemonia dos e para os subalternos. A investigação em âmbito filosófico-político terá como base teórica o legado gramsciano e, como método de orientação da pesquisa, a filosofia da práxis.

PALAVRAS-CHAVE: Gramsci, Crise Orgânica, Hegemonia.

ABSTRACT: Aiming to understand the factors that originated Fascism in Italy and the defeats of the labor movement in Europe, the Italian philosopher Antonio Gramsci promoted a microscopic analysis of these phenomena and the dimensions they reached in the period of the First and subsequent War, to investigate the factors that were associated and characterized the crisis, triggered by them. These would be some of the issues that would receive the attention of the Sardinian author in his work The Prison Notebooks, in which he would construct precious notes about the capitalist crisis, which for him would not only be a sporadic crisis typical of the system but an organic crisis to be followed of hegemonic power loss. In that work, he shows that the so-called crisis of hegemony also triggers economic, political, command, authority, etc. types of crises. Therefore, it must be interpreted as an organic movement that develops itself in a complex historical process, with its multiplicity of components and interrelations at the global level, and not only as an immediate and conjunctural phenomenon, hence it is provoked by a sum of questions which is accumulated molecularly. The author of the Prison Notebooks points

\footnotetext{
${ }^{1}$ Profa. do Programa de Pós Graduação em Filosofia. Instituto de Filosofia. Universidade Federal de Uberlândia. Doutora em Filosofia pela Universidade Estadual Paulista "Julio Mesquita" - Unesp-Campus Araraquara-SP. Email: helpramos@yahoo.com.br.
} 
out as a failure of the policy of the ruling class the imposition of the consensus of the masses by force; the political organization of large masses who were previously passive and who started to move, although without a precise political will; or even because the antagonistic forces proved incapable of organizing this disorder in their favor. The objective of this article is to explain the process of development of the organic crisis and the inherent loss of hegemony, and to demonstrate the possibility of building the hegemony from and for the subordinates. Philosophical-political research will have as its theoretical basis the Gramscian legacy and, as a method of orienting research, the philosophy of praxis.

KEYWORDS: Gramsci; organic crisis; Hegemony

Em sua investigação sobre as origens do Fascismo, o marxista Antonio Gramsci (18911937) buscava entender os fenômenos políticos que desencadearam a Primeira Guerra Mundial e as derrotas do movimento operário europeu, especialmente na obra Cadernos do Cárcere ${ }^{2}$, evidenciando no centro desta a concepção de crise orgânica, a qual compreende a Revolução Russa, greves, guerras civis desencadeadas na Europa pós-guerra, passando pela decomposição e transformação do Estado liberal nos países europeus até desembocar na crise econômica iniciada em 1929, episódios que remeteram imediatamente à crise de hegemonia ${ }^{3}$, isto é, de Estado, de comando, de autoridade, etc. Foi então que, procurando conhecer os elementos constitutivos dessa crise e a dimensão que ela atingiu, Gramsci empreendeu uma análise criteriosa dos fatores que a desencadearam durante e após a Guerra.

Perseguindo esses elementos, ele percebeu que no período do pós-guerra os princípios dessa crise provocam uma "ruptura entre as massas populares e as ideologias dominantes" (GRAMSCI, Q 3, §34, V. I,p. 311 [CC 3, §34, V 3, 2000, p. 184]), um rompimento que deu lugar a uma situação de "intervalo" que abriu inúmeras possibilidades de saída da crise. Ao invés disso, esta desembocaria na crise da bolsa de valores de 1929, à qual se somaramoutros elementos que dificultaram a sua superação. Por isso, no Caderno 15, Gramsci deu especial atenção aoseventos que assumiram o nome de crise e que se prolongaram de forma catastrófica, evitando apontar uma definição, causa ou origem única para estes eventos. Entendia ele que se

\footnotetext{
${ }^{2}$ Ao longo desse artigo, a obra Cadernos do cárcere de Antonio Gramsci será citada com a letra Q seguida pelo número: do caderno, parágrafo, volume e página, em referimento à Edição crítica italiana, coordenada por $\mathrm{V}$. Gerratana, da obra de GRAMSCI, A. Quaderni del cárcere. 4 vols., Torino: Einaudi, 1975/2001c. Na seqüência desta, serão expostos os mesmos dados da obra traduzida para o português, identificadas pelas letras CC. Em alguns casos pode-se colocar apenas uma ou outra versão.

3“'O termo hegemonia deriva do grego eghestai, que significa 'conduzir', 'ser guia', 'ser líder'; ou também do verbo eghemoneo, que significa 'ser guia', 'preceder', 'conduzir', e do qual deriva 'estar à frente', 'comandar', 'ser o senhor'. Por eghemonia, o antigo grego entendia a direção suprema do exército. Trata-se, portanto, de um termo militar. Hegemônico era o chefe militar, o guia e também o comandante do exército. Na época das guerras do Peloponeso, falou-se de cidade hegemônica para indicar a cidade que dirigia a aliança das cidades gregas em luta entre si" (GRUPPI, 1980, p. 1). No final do século XIX, o termo hegemonia passaria a ser entendido como supremacia, tendo sido usada com esse sentido pelos marxistas russos, entre eles Lênin.
} 
tratavade um processo (e não de um evento)com muitas manifestações e no qual causas e efeitos se interligavam e se sobrepunham, por isso simplificá-los significariafalseá-los.Para ele, no momento em que se diagnostica a crise de um "princípio", deveria-se analisar o modo e as razões pelas quais os aparelhos hegemônicos não conseguem mais formar o consenso por meios normais.

Assim, perseguindo os fatores estruturais da crise orgânica, em especial, a interrupção da capacidade expansiva dos quadros sociais como elemento dinâmico da modernidade burguesa, que é interrompida quando se inicia a "crise do Ocidente" (GRAMSCI, Q 1, §76, p. 83 [CC 1, §76, V. 3, 2000, p. 120]) e se rompe a unidade cristã católica medieval a partir da Reforma. Por isso, Gramsci põe-se a analisar o período pós Reforma Protestante, depois de quase dois séculos de guerras religiosas, mostrando que teria ocorrido no Ocidente uma segunda unidade, de outra natureza, que atingiu profundamente toda a vida europeia, a despeito das resistências. É nesta nova unidade em crise que os católicos pretendiam solucionar, que estão os resíduos fósseis daquela primeira unidade histórica que já se encontrava definitivamente superada.

Esta crise se apoia em três elementos fundamentais: nos espíritos crítico, científico e capitalista ou industrial. Para Gramsci, o espírito crítico não está mais presente, por isso as elites espirituais do Ocidente sofrem de desequilíbrio e de desarmonia entre a consciência crítica e a ação, o que, para ele, seria uma crise do "historicismo" devido à oposição entre "sentimento", "paixão" e consciência crítica. Porém, indaga o italiano: essa crise não estaria, antes de tudo, ligada ao mito do progresso indefinido e do otimismo que daí decorreria, ou seja, de uma forma de religião? Mais do que de uma crise do historicismo e da crítica?

Em sua resposta afirma que a consciência crítica se restringia, na verdade, a um pequeno e restrito grupo hegemônico; o “'aparelho de governo' espiritual se rompe e há crise, mas ela é de difusão, o que levará a uma nova 'hegemonia' mais segura e estável” (GRAMSCI, Q 1, §76, V. I, p. 84 [CC 1, §76, V. 3, 2000, p. 121]).

Trata-se de uma crise de época, por isso em seu Caderno 6 (escrito de 1930 a 1932), Gramsci relembra uma intervenção de Benedetto Croce (1866-1952) proferida no Congresso Internacional de Filosofia de Oxford em 1930, à qual destinaria uma severa crítica no tocante à atitude prática e filosófica croceana. Isso porque, para ele, Croce acredita que filosofia e ideologia são idênticas, e mais que isso, que a filosofia é apenas um "instrumento prático" de organização e de ação: de organização de um partido, uma espécie de “internacional de partidos, e de uma linha de ação prática", ou melhor, um "manifesto político de uma união internacional 
dos grandes intelectuais de todas as nações, especialmente da Europa; e não se pode negar que este possa tornar-se um partido importante e ter uma função não desprezível" (GRAMSCI, CC 6, §10, V. 1, 2001a, p. 435]). E isso por Gramsci entender que, no mundo moderno, ocorre um fenômeno semelhante àquele

\begin{abstract}
da separação entre 'espiritual' e 'temporal' na Idade Média: fenômeno muito mais complexo do que o de então, na medida em que se tornou mais complexa a vida moderna. Os grupos sociais regressivos e conservadores se reduzem cada vez mais à sua fase inicial econômico-corporativa, ao passo que os grupos progressistas e inovadores se encontram ainda na fase inicial exatamente econômico-corporativa; os intelectuais tradicionais, separando-se do grupo social ao qual haviam dado até agora a forma mais alta e compreensiva e, portanto, a consciência mais ampla e perfeita do Estado moderno, na realidade efetuamum ato de incalculável alcance histórico: assinalam e confirmam a crise estatal em sua forma decisiva. Mas estes intelectuais não têmnem a organização eclesiástica nem coisa alguma que a ela se assemelhe, $\mathrm{e}$ nisto a crise moderna é agravada em comparação com a crise medieval, que se desenrolou por muitos séculos até a Revolução Francesa, quando o grupo social que após o século XI, foi a força motriz econômica da Europa e pôde apresentar-se como 'Estado' integral, com todas as forças intelectuais e morais necessárias e suficientes para organizar uma sociedade completa e perfeita. Hoje, o 'espírito' que se destaca do 'temporal' e dele se distingue de modo autônomo é algo não orgânico, descentrado, uma poeira instável de grandes personalidades culturais 'sem papa' e sem território. Esse processo de desintegração do Estado moderno, portanto, é muito mais catastrófico do que o processo histórico medieval, que era desintegrativo e integrativo ao mesmo tempo, dado o grupo específico que era o motor do processo histórico e [...] o tipo de Estado que existia depois do século XI na Europa, que não conhecia a centralização moderna e poderia ser chamado mais de "federação das classes dominantes", do que de Estado de uma só classe dominante (GRAMSCI, CC 6, §10, V. 1, 2001a, p. 435-6]).
\end{abstract}

Esse conjunto de problemas parece convencer Gramsci a definir como "orgânica" a crise que atinge toda a sociedade capitalista-burguesa, em especial a europeia a partir dos anos 1870 , analisada por ele.

O que Gramsci quer saber é quando começou a crise. Para ele, a crise como tal não tem data de início, mas é o resultado de um processo complexo, por isso seria equivocado e mesmo tendencioso identificar manifestações mais expressivas da crise como sendo a própria crise. Para alguns analistas, a crise de 1929 seria o começo, e sua causa residiria no "americanismo". Para Gramsci,esta seriaapenas "uma das manifestações do desenvolvimento da crise, e nada mais" (GRAMSCI, Q 15, §5, V. III, p. 1.755-6 [CC 15, §5, V. 4, 2015, p. 317]). Nesse caso, a crise de hegemonia aparece como "crise de comando e de direção na qual o consenso espontâneo sofre uma crise" (Q 4, §48, 476). A seu ver, todo o pós-guerra é crise, com tentativas de superá-la que às vezes tem sucesso num ou noutro país. Para alguns, e talvez com razão, 
a própria guerra é uma manifestação da crise, ou melhor, a primeira manifestação; a guerra foi precisamente a resposta política e organizativa dos responsáveis. (Isto mostraria que é difícil separar nos fatos a crise econômica das crises políticas, ideológicas, etc., embora isto seja possível científicamente, ou seja, mediante um trabalho de abstração) (GRAMSCI, Q 15, §5, V. III, p. 1.755-6 [CC 15, §5, V. 4, 2015, p. 317]).

Perseguindo a origem da crise, Gramsciafirma que ela parece ter

origens 'técnicas', isto é, nas respectivas relações de classe, mas [já no início], as primeiras manifestações ou previsões deram lugar a [inúmeros] conflitos e intervenções legislativas, que [não a determinaram, mas] lançaram mais luz sobre a própria 'crise', ou acentuaram alguns de seus fatores (GRAMSCI, Q 15, §5, V. III, p. $1.756[$ CC 15, §5, V. 4, 2015, p. 317]).

Daí decorrem três pontos queprecisam ser esclarecidos com exatidão: "1) que a crise é um processo complexo; 2) que se inicia pelo menos com a guerra, ainda que esta não seja sua primeira manifestação; 3) que a crise tem origens internas, nos modos de produção e, portanto, de troca, e não em fatos políticos e jurídicos" (GRAMSCI, Q 15, §5, V. III, p. 1.756 [CC 15, $\S 5$, V. 4, 2015, p. 317]). Nessa primeira aparição, crise indica, segundo sua “concepção médica original”, nos dizeres de Gramsci (CC 15, §5, 2015, p. 317), o ponto culminante e resoluto de um processo desencadeado por uma súbita mudança que decide pelo decurso da doença. Crise indica aqui também uma situação de mobilização coletiva, na qual as massas subitamente se fluidificam, revelando e acelerando processos estruturais antes lentos e imperceptíveis.

A esses pontos ele acrescenta as contradições fundamentais da sociedade capitalista avançada, cuja vida econômica tem como premissa o internacionalismo, ou seja, o cosmopolitismo, por isso a vida estatal se desenvolveu no sentido do "nacionalismo", da "autosufiência". Daí decorre que uma das caracterísitcas mais visíveis da "crise atual"

é apenas a exasperação do elemento nacionalista (estatal-nacionalista) na economia: quotas de importação e de exportação, clearing, restrição ao comércio de divisas, comércio equilibrado apenas entre dois Estdos, etc. Então se poderia dizer, o que seria o mais exato, que a 'crise' é tão somente a intensificação quantitativa de certos elementos, nem novos nem originais, mas sobretudo a intensificação de certos fenômenos, enquanto outros, que antes apareciam e operavam simultaneamente com os primeiros, neutralizando-os, tornaram-se inoperantes ou desapareceram inteiramente. Em suma, o desenvolvimento do capitalismo foi uma 'crise' contínua, (...) ou seja, um rapidíssimo movimento de elementos que se equilibravam e se neutralizavam (GRAMSCI, Q 15, §5, V. III, p. 1.756-7 [CC 15, §5, V. 4, 2015, p. 318]).

Neste movimento, podem predominar ou desaparecer alguns elementos, e entãosurgem os eventos que configuram as “crises", os quais dependem do equilíbrio entre seus 
aspectos constitutivos: monetário, financeiro, produtivo etc. E esses aspectos não podem ser desconsiderados devido à divisão internacional do trabalho e às funções que cada país exerce dentro desta divisão. Contudo, asseverao italiano, “o problema fundamental da 'crise' é o produtivo; e, na produção, o desequilíbrio entre indústrias dinâmicas (nas quais o capital constante aumenta)e indústrias estacionárias (nas quais conta muito a mão-de-obra imediata)"'(GRAMSCI, Q 15, §5, V. III, 2001c, p. 1.756-7 [CC 15, §5, Vol. 4, 2015, p. 318]).E os países onde predominam as indústrias dinâmicas são os mais atingidos pelas "crises" devido ao alto grau de competitividade e de desenvolvimento de forças produtivas.

Ante esse quadro, as tentativas de superar a crise de forma orgânica, isto é, de reconstruir sua base nacional em um novo modelo hegemônico, se apresentam por meio de revoluções passivas, que é uma categoria gramsciana de novo cunho. Embora tal concepção originária tenha sido cunhada por Vicenzo Cuoco, Gramsci a toma de empréstimo, mas "não é apenas uma inspiração, pois o conceito é completamente modificado e enriquecido" (GRAMSCI, Q 15, §17, V. III, 2001c, p. 1.775) pelo filósofo sardo. Ele mostra que, em diversos contextos, a Itália fascista utilizou-se do corporativismo que serve de "modelo" para toda a Europae Estados Unidos e, com a reorganização fordista que promoveu o nexo entre produção e política, se abriram processos de revolução passiva, consistentes especialmente na capacidade de propor novamente à sociedade nacional um modelo de desenvolvimento que fosse, também, uma resposta possível diante do avanço das classes subalternas.

A preocupação de Gramsci em investigar as crises e revoluções passivas atrevessam todo o seu trabalho carcerário orientada por duas grandes polaridades, nas quais se condensa o significado dos conflitos abertos na Itália, na Europa e no mundo daquela época; e, que, nas suas interações, se constituem, de um lado, em espaços de inovações da teoria política e social; e de outro, novas combinações de "progresso" e "reações" de "velho" e de "novo" que deixam entrever formas inéditas de relações entre forças sociais e políticas organizadas.O aspecto dessa crise moderna está ligado à crise de autoridade, porque

Se a classe dominante perde o consenso, ou seja, se não é mais 'dirigente', mas unicamente 'dominante', detentora de pura força coercitiva, isto significa exatamente que as grandes massas se destacaram das ideologias tradicionais, não acreditam mais no que antes acreditavam [...]. A crise consiste justamente no fato de que o velho morre e o novo não pode nascer: neste interregno, verificam-se os fenômenos patológicos mais variados (GRAMSCI, Q 3, §34, V. I, 2001c, p. 311 [CC 3, § 34, V. 3, 2000, p. 184]).

Nas crises orgânicas verifica-se uma situação complexa na qual, embora tendo perdido o consenso, a classe dominante conserva a autoridade, pela qual não é mais dirigente, mas 
continua a ser dominante. Ao mesmo tempo, a classe dominada adquire certa quota de consenso, mas não possui a autoridade pela qual seria já dirigente. Nesse cenário, se desenvolve uma dialética que não se refere a uma pura e simples relação baseada na força, mas numa dinâmica que gira em torno do nexo força-consenso. Assim, se o "novo" demora a se firmar, tanto o "velho" quanto o "novo" se encontram convivendo numa situação de "ceticismo diante de todas as teorias e as fórmulas gerais e como limitação ao puro fato econômico e à política", e esta redução à economia e à política significa, precisamente, que houve uma "redução das superestruturas mais elevadas às mais aderentes à estrutura, isto é, [à] possibilidade e necessidade de formação de uma nova cultura" (GRAMSCI, Q 3, § 34, V. I, 2001c, p. 311 [CC $3, \S 34$, V. 3, 2000, p. 184-5]).

A crise é produzida, exatamente, por uma fratura entre a estrutura e a superestrutura causada pelo aparecimento de contradições que aparecem no momento em que a superestrutura não mais se conforma à estrutura. $\mathrm{E}$ as condições necessárias para o aparecimento de uma crise orgânica são, na avaliação de Gramsci, 1) o fracasso da política da classe dirigente; 2) a organização das classes subalternas, sem a qual a crise não causará repercussões no seio da classe dirigente. Em outras palavras, a crise explode

\begin{abstract}
ou porque a classe dirigente fracassou em algum grande empreendimento político para o qual impôs pela força o consenso das grandes massas (como a guerra), ou porque amplas massas, (sobretudo de camponeses e de pequeno-burgueses intelectuais) passaram subitamente da passividade política para certa atividade e apresentam reivindicações que, em seu conjunto desorganizado, constituem uma revolução (GRAMSCI, Q 13, § 23, V. III, 2001c, p. 1.603 [CC 13, § 23, V. 3, 2000, p. 60]).
\end{abstract}

Neste caso, fala-se de “'crise de autoridade': e isso é precisamente a crise de hegemonia, ou crise do Estado em seu conjunto" (GRAMSCI, Q 13, §23, V. III, p. 1.603 [CC 13, §23, V. 3, 2000, p. 60]). O filósofo italiano exemplifica essa situação apresentando os acontecimentos ocorridos na Itália no final da Primeira Guerra Mundial, quando havia irrompido uma profunda crise orgânica, desencadeada porque

1) grandes massas, anteriormente passivas, entraram em movimento, mas num movimento caótico e desordenado, sem direção, isto é, sem uma precisa vontade política coletiva; 2 ) porque classes médias que tiveram na guerra funções de comando e de responsabilidade foram privadas disto com a paz, ficando desocupadas justamente depois de fazer uma aprendizagem de comando, etc.; 3 ) porque as forças antagônicas se revelaram incapazes de organizar em seu proveitoesta desordem de fato (GRAMSCI, Q 7, §80, V. II, 2001c, p. 912-13 [CC 7, §80, V. 3, 2000, p. 264-5]). 
O problema, então, era reconstruir o aparelho hegemônico destes elementos antes passivos e apolíticos, e isto não ocorreria sem que se fizesse uso da força, "mas esta força não podia ser a 'legal'”, pois em cada Estado o conjunto das relações sociais era diferente, por issotambém deveriam ser diferentes "os métodos políticos de emprego da força e a combinação das forças legais e ilegais". Assim, quanto maior é a massa de apolíticos, maior deve ser a contribuição das forças ilegais, quanto maiores são as forças politicamente organizadas e educadas, tanto mais é preciso "resguardar" o Estado legal.

Por conseguinte, quando a classe dirigente perde a capacidade de fazer toda a sociedade avançar porque não garantiu a satisfação das necessidades vitais nem ampliou "os próprios quadros para a contínua ocupação das novas esferas de atividade econômicoprodutiva", o grupo dominante deixa de exercer essa função, e com isso, "o bloco ideológico tende a fragmentar-se, e entãoa 'coerção pode substituir a 'espontaneidade' sob formas cada vez menos disfarçadas e indiretas, até as medidas propriamente policiais e os golpes de Estado" (GRAMSCI, Q 19, §24, V. III, 2001c, p. 2.012 [CC 19, §23, V. 5, 2014, p. 64]). Neste sentido é que as crises orgânicas se apresentam com características próprias de uma crise de hegemonia, por isso "em cada país o processo é diferente, embora o conteúdo seja o mesmo. E o conteúdo é a crise de hegemonia da classe dirigente" (GRAMSCI, Q 13, §23, p. 1.603 [CC 13, §23, V. 3, 2000, p. 60]). Nesses momentos, a crise cria situações imediatas perigosas, pois

os diversos estratos da população não possuem a mesma capacidade de se orientar rapidamente e de se reorganizar com o mesmo ritmo. A classe dirigente tradicional, que tem numeroso pessoal treinado, muda homens e programas e retoma o controle que lhe fugia com uma maior rapidez do que a que verifica as classes subalternas; faz talvez sacrifícios, expõe-se a um futuro obscuro com promessas demagógicas, mas mantém o poder, reforça-o momentaneamente e dele se serve para esmagar o adversário e desbaratar seus dirigentes, que não podem ser muito numerosos nem adequadamente treinados. A unificação das tropas de muitos partidos sob a bandeira de um único partido,que representa melhor e sintetiza as necessidades de toda a classe, é um fenômeno orgânico e normal, ainda que seu ritmo seja muito rápido e quase fulminante em relação aos tempos tranquilos: representa a fusão de todo um grupo social sob uma só direção, considerada a única capaz de resolver um problema vital dominante e de afastar um perigo mortal (GRAMSCI, Q 13, §23, V. III, p. 1.603 [CC $13, \S 23$, V. 3, 2000, p. 60-61]).

Mas, quando a crise não encontra esta solução orgânica, mas

Sim a do chefe carismático, isto significa que existe um equilíbrio estático (cujos fatores podem ser muito variados, mas entre os quais prevalece a imaturidade das forças progressistas), que nenhum grupo, nem o conservador nem o progressista, dispõe da força necessária para vencer e que até o grupo conservador tem necessidade de um senhor (cf. o 18 Brumário de Luís Napoleão) (GRAMSCI, Q 13, §23, p. 1.603 [CC 13, §23, V. 3, 2000, p. 61]) 
Foi o que ocorreu, também, com o fascismo italiano. Aqui é necessário relembrar que esta ordem de fenômenos liga-se a uma das questões mais importantes concernentes ao partido político, isto é,

à capacidade do partido de reagir contra o espírito consuetudinário, contra as tendências a se mumificar e tornar anacrônico. Os partidos nascem e se constituem como organização para dirigir a situação em momentos historicamente vitais para as classes; mas nem sempre eles sabem adaptar-se às novas tarefas e às novas épocas, nem sempre sabem desenvolver-se de acordo com o desenvolvimento do conjunto das relações de forças (e, portanto, a posição relativa de suas classes) no país em questão ou no campo internacional. Quando se analisam estes desenvolvimentos dos partidos, é necessário distinguir: o grupo social, a massa partidária, a burocracia e o EstadoMaior do partido. A burocracia é a força consuetudinária e conservadora mais perigosa; se ela chega a se constituir como um corpo solidário, voltado para si mesmo e independente da massa, o partido termina por se tornar anacrônico e, nos momentos de crise aguda, é esvaziado de seu conteúdo social e resta como que solto no ar (GRAMSCI, Q 13, §23, V. III,p. 1.603 [CC 13, §23, V. 3, 2000, p. 61]).

Como exemplo disso, Gramsci assinala o que aconteceu com uma série de partidos alemães em função da expansão do hitlerismo. Ou com partidos franceses que, naquela época, encontravam-se mumificados ou anacrônicos. Assim, ao analisar esta ordem de acontecimentos, o autor italiano chama a atenção para o fato de, em geral, não se dar o devido valor ao elemento burocrático, civil e militar, e de um movimento político ou um governopoder ser de caráter militar ainda que o exército, propriamente dito, não participe dele abertamente.

Em determinadas situações convém não expor o exército, não fazê-lo sair dos quadros constitucionais, não levar a política aos quartéis, a fim de manter a homogeneidade entre oficiais e soldados num terreno de aparente neutralidade e superioridade sobre as facções, embora seja o exército, ou seja, o Estado-Maior e a oficialidade, que determina a nova situação e a domina. Ademais, o exército em algumas circunstâncias deve "fazer política; o exército deve precisamente defender a Constituição, isto é, a forma legal do Estado, com suas instituições correspondentes; por isso, a chamada neutralidade significa somente o apoio à parte retrógrada" (GRAMSCI, Q 13, §23, V. III,p. 1.603 [CC 13, §23, V. 3, 2000, p. 62-3]).

Retomando o nosso argumento central, podemos dizer que a crise de hegemonia se manifesta no momento em que a sociedade civil priva o Estado do apoio constituído pela direção, pela organização do consenso de massa e pela formação ideológica de funcionários e quadros dirigentes. Está assim aberta a estrada para a crise orgânica, em consequência da qual o "Estado, ainda que os governantes digam o contrário, não tem uma concepção unitária, coerente e homogênea, razão pela qual os grupos intelectuais estão desagregados em vários 
estratos e no interior de um mesmo estrato" (GRAMSCI, Q 11, §12, V. II, 2001c, p. 1.394 [CC 11, §12, V. 1, 2001a, p. 112]). O exemplo histórico que Gramsci utiliza para ilustrar o problema é o período do pós-guerra, quando

o aparelho hegemônico se estilhaça e o exercício da hegemonia torna-se permanentemente difícil e aleatório. O fenômeno é apresentado e tratado com vários nomes e em seus aspectos secundários e derivados. Os mais triviais são: 'crise do princípio de autoridade' e 'dissolução do regime parlamentar'. Naturalmente, descrevem-se do fenômeno tão somente as manifestações 'teatrais' no terreno parlamentar e do governo político, manifestações que são explicadas precisamente através da falência de alguns 'princípios' (parlamentar, democrático, etc.) e da 'crise' do princípio de autoridade [...]. A crise se apresenta, praticamente, na dificuldade cada vez maior dos próprios governos: ela tem sua origem imediata na multiplicação dos partidos parlamentares e nas crises internas permanentes de cada um destes partidos (GRAMSCI, Q 13, §37, V. III, p. 1.638-9 [CC 13, §37, V. 3, 2000, p. 95-6]).

Assim, verifica-se no interior de cada partido o que se verifica no Parlamento como um todo, ou seja, dificuldades de governo e instabilidade de direção. E as formas deste fenômeno são também, em certa medida, de corrupção e de dissolução moral, por que

\begin{abstract}
cada fração de partido acredita possuir a receita infalível para deter o enfraquecimento do partido como um todo e recorre a todos os meios para assumir sua direção ou, pelo menos, participar da direção, do mesmo modo como, no Parlamento, o partido pensa que deve ser o único a formar o governo para salvar o país, ou pelo menos, pretende, para dar apoio ao governo, participar dele do modo mais amplo possível; disso resultam acordos cavilosos e minuciosos, que não podem deixar de ser personalistas a ponto de parecer escandalosos e que, frequentemente, são inconfiáveis e traiçoeiros. Talvez, na realidade, a corrupção pessoal seja menor do que parece, já que todo o organismo político está corrompido pelo esfacelamento da função hegemônica. Seria possível também justificar o fato de que os interessados em que a crise se resolva de seu próprio ponto de vista finjam acreditar e proclamar em voz alta que se trata da ‘corrupção’ e da ‘dissolução’ de uma série de ‘princípios’ (imortais ou não): cada um é melhor juiz na escolha das armas ideológicas mais apropriadas ao fim que pretende alcançar, e a demagogia pode ser considerada uma excelente arma. Mas a coisa tornase cômica quando o demagogo não sabe que é demagogo e atua na prática como se fosse verdade que na realidade dos fatos o hábito faz o monge e o chapéu, o cérebro (GRAMSCI, Q 13, §37, p. 1.639 [CC 13, §37, V. 3, 2000, p. 96-7]).
\end{abstract}

Assim, põe-se um novo problema de hegemonia que desloca a base histórica do Estado, desse modo tem-se uma forma extrema de sociedade política: "ou para lutar contra o novo e conservar o que oscila, fortalecendo-o coercitivamente, ou como expressão do novo para esmagar as resistências que encontra ao desenvolver-se" (GRAMSCI, 2000, V. 3. C 7, \#28, p. 262-3). No caso italiano, essa disputa hegemônica deveria seria travada entre o fascismo e a classe operária, para conservar ou mudar o poder.

E isso porque a autonomia política moderna torna mais complexas as crises revolucionárias nas sociedades ocidentais. Com efeito, ao defini-las, o marxista italianofaz 
referência à ideia de crise orgânica que não tem solução rápida, mas que se dissolve por meio de uma degradação paulatina do antigo bloco histórico ${ }^{4}$. Assim, se a crise orgânica se apresenta em consequência de contradições na estrutura do modo de produção, aparecerá também na superestrutura, na política e na ideologia, ou seja, como crise de hegemonia, uma vez que quando a classe dominante perde o consenso, deixa de ser dirigente e passa a ser apenas dominante, por isso faz uso da coerção. Tal crise acontece porque as massas se separaram das ideologias tradicionais, por isso a crise de hegemonia, como expressão política da crise orgânica, é própria das sociedades complexas que têm participação política organizada, e a opinião pública

\begin{abstract}
está estritamente ligada à hegemonia política, ou seja, é o ponto de contato entre a 'sociedade civil' e a 'sociedade política', entre o consenso e a força. O Estado, quando quer iniciar uma ação pouco popular, cria previamente a opinião pública adequada, ou seja, organiza e centraliza certos elementos da sociedade civil. (...) a opinião pública como hoje se entende nasceu às vésperas da queda dos Estados absolutistas, isto é, no período de luta da nova classe burguesa pela hegemonia política e pela conquista do poder.A opinião pública é o conteúdo político da vontade política pública, que poderia ser discordante: por isto, existe luta pelo monopólio dos órgãos da opinião pública - jornais, partidos, Parlamento -, de modo que uma só força modele a opinião e, portanto, a vontade política nacional, desagregando os que discordam numa nuvem de poeira individual e inorgânica (GRAMSCI, 2000, V. 3. C 7, \#83, p. 265).
\end{abstract}

Essa crise tem longo período de maturação, o que permite a luta por espaços e posições, isto é, por parcelas da sociedade, num movimento de avanços e recuos. E como as demais crises, a de hegemonia pode ter diversas soluções, de modo que a classe dominante pode governar coercitivamente ou recuperar a hegemonia mediante concessões, manobras ou reformas. Para tanto, conta com a incapacidade das forças adversárias em apresentar soluções construtivas. Dito de outro modo:

\begin{abstract}
na política subsiste a guerra de movimento enquanto se trata de conquistar posições não decisivas e, portanto, não se podem mobilizar todos os recursos de hegemonia e do Estado; mas quando, por uma razão ou por outra, estas posições perderam seu valor e só aquelas decisivas têm importância, então se passa à guerra de assédio, tensa, difícil, em que se exigem qualidades excepcionais de paciência e espírito inventivo. Na política o assédio é recíproco, apesar de todas as aparências, e o simples fato de que o dominante deva ostentar todos os seus recursos demonstra o cálculo que ele faz do adversário (GRAMSCI, 2000, V. 3. C 6, \#138, p. 255-6).
\end{abstract}

\footnotetext{
${ }^{4} \mathrm{O}$ conceito de "Bloco Histórico" gramsciano pode ser entendido em sentidos diversos, embora interligados dialeticamente, a saber: como a totalidade concreta composta pela articulação da infra-estrutura material e das superestruturas político-ideológicas; e como uma aliança de classes sob a hegemonia de uma classe fundamental no modo de produção, cujo objetivo é conservar ou revolucionar uma formação econômico-social. A ligação dialética entre ambos ocorre à medida que a construção de um bloco histórico, no segundo sentido, requer a criação de uma nova articulação entre economia e política, entre infra e superestrutura.
} 
Por meio dessa crise estrutural, as classes dominadas podem ampliar alianças e consensos, invertendo em benefício próprio as relações de hegemonia para tornarem-se classes dirigentes e dominantes. Isso porque a construção da hegemonia pressupõe

\begin{abstract}
Indubitavelmente que sejam levados em conta os interesses e as tendências dos grupos sobre os quais a hegemonia será exercida, que se forme um certo equilíbrio de compromisso, isto é, que o grupo dirigente faça sacrifícios de ordem econômicocorporativa; mas também é indubitável que tais sacrifícios e tal compromisso não podem deixar de envolver o essencial, dado que, se a hegemonia é ético-política, não pode deixar de ser também econômica, não pode deixar de ter seu fundamento na função decisiva que o grupo dirigente exerce no núcleo decisivo da atividade econômica. O economicismo apresenta-se de muitas outras formas, além do liberalismo e do sindicalismo teórico. Dele fazem parte toda as formas de abstencionismo eleitoral [...]. [Mas,] nem sempre o economicismo é contrário à ação política e ao partido político, embora esse seja considerado como mero organismo educativo de tipo sindical (GRAMSCI, 2000, V. 3. C 13, \#18, p. 48).
\end{abstract}

Essa hegemonia constrói um determinado bloco histórico que abarca a totalidade social, seus elementos políticos e culturais e se mantém coeso graças a essa direção que representa a unificação. Na guerra de posições que atravessa uma crise de hegemonia, as classes dominadas devem preparar, de modo progressivo, soluções para a tomada do poder, já que no capitalismo avançado o poder não pode ser obtido de repente, mas articulado gradualmente. Entretanto, a guerra de posições

exige enormes sacrifícios de massas imensas de população; por isto, é necessária uma concentração inaudita da hegemonia e, portanto, uma forma de governo mais 'intervencionista', que mais abertamente tome a ofensiva contra os opositores e organize permanentemente a 'impossibilidade' de desagregação interna: controles de todo tipo, políticos, administrativos, etc., reforço das 'posições' hegemônicas do grupo dominante, etc. (GRAMSCI, 2000, V. 3, C 6, \#138, p. 255).

Essa crise orgânica, cuja perda de poder hegemônico lhe é inerente, apresenta-se como momento propício ao empreendimento da guerra de posições, que deverá ser levada a cabo pelos intelectuais orgânicos e tradicionais, via partido político, com vistas à conquista do consenso em torno da construção da hegemonia dos subalternos, pois

a unidade de teoria e prática não é um dado mecânico, mas um devir histórico, que tem a sua fase elementar e primitiva no sentimento de 'distinção', de 'separação', de independência quase instintiva, e progride até a aquisição real e completa de uma concepção do mundo coerente e unitária. É por isso que se deve chamar a atenção para o fato de que o desenvolvimento político do conceito de hegemonia representa, para além do progresso político-prático, um grande progresso filosófico, já que implica e supõe necessariamente uma unidade intelectual e uma ética adequada a uma 
concepção do real que superou o senso comum e tornou-se crítica, mesmo que dentro de limites ainda restritos (GRAMSCI, 2001a, V. 1. C 11,\#12, p. 103-4).

Portanto, a conquista da hegemonia, a transformação da classe dominada em dirigente antes da tomada do poder, é o elemento central da estratégia gramsciana de transição socialista. Essa estratégia é a única que oferece resultados mais estáveis e seguros, haja vista que "na política a 'guerra de posição' uma vez vencida, é definitivamente decisiva” (GRAMSCI, 2000, V. 3. C 6,\#138, p. 255). Antes, porém, a classe operária dirigente, hegemônica, deve tornar-se classe nacional, isto é, deve superar o corporativismo e assumir como seus todos os problemas da nação. Os intelectuais que promoverão essa transformação no interior do Partido político de vanguarda devem ter em mente que

a guerra de posição não é constituída apenas pelas trincheiras propriamente ditas, mas por todo o sistema organizativo e industrial que está por trás do exército alinhado, sendo imposta, sobretudo, pelo tiro rápido dos canhões, das metralhadoras, dos mosquetões, pela concentração das armas num determinado ponto, bem como pela abundância do abastecimento, que permite a rápida substituição do material perdido depois de uma penetração e de um recuo. Um outro elemento é a grande massa de homens que participam do alinhamento, de valor muito desigual e que só podem operar precisamente como massa (GRAMSCI, 2000, V. 3. C 13, \#24, p. 72).

Por isso, o político italiano defende que é primordial fazer uma política correspondente ao Estado ampliado, próprio do capitalismo avançado, que apresenta uma generalização das lutas de classes, diferentemente do que ocorre nos países de tipo oriental, onde é possível o ataque frontal. Trata-se de estudar com profundidade quais são os elementos da sociedade civil que correspondem aos sistemas de defesa na guerra de posições. De analisar

'com profundidade' intencionalmente, já que tais elementos foram estudados: mas o foram ou a partir de pontos de vista superficiais e banais, assim como certos historiadores do vestuário estudam as extravagâncias da moda feminina, ou a partir de um ponto de vista 'racionalista', isto é, com a persuasão de que certos fenômenos são destruídos tão logo explicados 'de modo realista', como se fossem superstições populares (que, de resto, também não são destruídas por serem explicadas) (GRAMSCI, 2000, V. 3. C 13, \#24, p. 73).

Isso nos faz compreender por que, utilizando-se da burocracia do Estado francomaçônica - que é laica e democrática -, a burguesia do Estado pós-unitário lutou contra as pretensões da Igreja, provando que uma instituição privada pode desempenhar uma função política ideológica decisiva na organização política de uma classe por meio do aparelho de Estado e dos intelectuais. Esse exemplo mostra-nos como o aparelho de hegemonia se vincula 
ao aparelho estatal e que, através dos aparelhos privados como a Igreja, que lhe dão coesão, podem se tornar grandes aliados do Estado na sociedade civil. E isso ocorre quase sempre

\begin{abstract}
que um movimento 'espontâneo' das classes subalternas seja acompanhado por um movimento reacionário da ala direita da classe dominante, por motivos concomitantes: por exemplo, uma crise econômica determina, por um lado, descontentamento nas classes subalternas e movimentos espontâneos de massa, e, por outro, determina complôs de grupos reacionários que exploram o enfraquecimento objetivo do Governo para tentar golpes de Estado. Entre as causas eficientes destes golpes de Estado deve-se pôr a renúncia dos grupos responsáveis a dar uma direção consciente aos movimentos espontâneos e, portanto, a torná-los um fator político positivo (GRAMSCI, 2000, V. 3. C 3, \#48, p. 197).
\end{abstract}

Isso foi o que ocorreu na Itália, quando a burguesia oriunda da revolução passiva, ante a ausência de amplas bases de massa, recorreu aos quase-partidos e à Igreja que eram aparelhos hegemônicos implantados na sociedade civil, sendo a Igreja detentora do aparelho de hegemonia da sociedade precedente. É desse modo que a hegemonia política da classe dominante passa pela combinação da força e do consenso, de uma combinação cujo termômetro é a opinião pública. Contudo, os modos de organização do consensopermanecem complexos, pois a hegemonia política, por apoiar-se em partidos políticos, passa por diversos órgãos da sociedade civil, uma vez que toda ação política participa de um movimento filosófico e cultural. Além disso, os partidos, por si só, são dispositivos complexos de ramificações diversas.

A solução dessa crise depende dos sujeitos coletivos, da capacidade destes para fazer política e envolver grandes massas na luta para conquistar parcelas da população, com o intuito de promover transformações na estrutura capitalista, pois a desagregação do Bloco Histórico depende da capacidade proletária de fazer política, de conquistar para si a hegemonia perdida, ou em vias de sê-lo, pela classe dominante.

E, como se viu, a conquista do poder não se dá de modo repentino, mas se realiza por meio de um processo prolongado de transformação revolucionária da sociedade, em que o Partido - como intelectual orgânico - deve conquistar para o seu projeto parcelas da sociedade civil, e, educando a massa através de uma reforma intelectual e moral, conquista a hegemonia proletária, necessária à guerra de posições rumo à conquista do poder estatal.

Nessa perspectiva entende-se porque o teórico italiano - utilizando a tradição de pensamento marxista - alarga e supera com originalidade o conceito de sociedade civil e a própria concepção de mundo das teorias liberais. A guerra de posições gramsciana e a conquista do poder do Estado nas sociedades capitalistas avançadas não se darão por um colapso repentino da dominação burguesa. Ao contrário, resultará de uma ocupação progressiva de espaços no 
interior da sociedade civil, visto que a expansão da hegemonia das classes subalternas, tal como a entende Gramsci, implica o acúmulo de posições na sociedade civil por um bloco histórico que, inicialmente, modifica a correlação de forças e termina por impor a direção de uma nova classe ou bloco de classes no Estado.

Cabe aos herdeiros de Gramsci trabalhar em condições históricas favoráveis ao empreendimento desuas indicações, em um conjunto articulado e consistente de formulações políticas e ideológicas concretas, porque o poder de atuação de um partido educador no interior do Estado ampliado depende, em certa medida, de sua capacidade de assimilar, criativamente, os elementos universais contidos na teoria política gramsciana.

\section{REFERÊNCIAS BIBLIOGRÁFICAS}

GRAMSCI, A.Cadernos do cárcere. Vol. 1. 2 ed. Trad. Carlos N. Coutinho; Marco Aurélio Nogueira; Luiz Sérgio Henriques.Rio de Janeiro: Civilização Brasileira, 2001a. 494p.

Cadernos do cárcere. Vol. 2. 2 ed. Trad. Carlos N. Coutinho; Marco Aurélio Nogueira; Luiz Sérgio Henriques.Rio de Janeiro: Civilização Brasileira, 2001b. 334p.

Cadernos do cárcere. Vol. 3. 1 ed. Trad. Carlos N. Coutinho; Marco Aurélio Nogueira; Luiz Sérgio Henriques. Rio de Janeiro: Civilização Brasileira, 2000. 428p.

Cadernos do cárcere. Vol. 4. 5 ed. Trad. Carlos N. Coutinho; Marco Aurélio Nogueira; Luiz Sérgio Henriques. Rio de Janeiro: Civilização Brasileira, 2015. 394p.

Cadernos do cárcere. Vol. 5. 3 ed. Trad. Carlos N. Coutinho; Marco Aurélio Nogueira; Luiz Sérgio Henriques. Rio de Janeiro: Civilização Brasileira, 2014.461p.

GRAMSCI, A.Quaderni del carcere. Vols. I, II, III e IV. Edizione critica dell'istituto Gramsci. A cura di GerRAtanA, Valentino. Torino: Giulio Einaudi, 1975 e 2001c. 3370p.

GRUPPI, Luciano. O conceito de hegemonia em Gramsci. 4 ed. Trad. Carlos N. Coutinho. Rio de Janeiro: GRAAL, 1978 